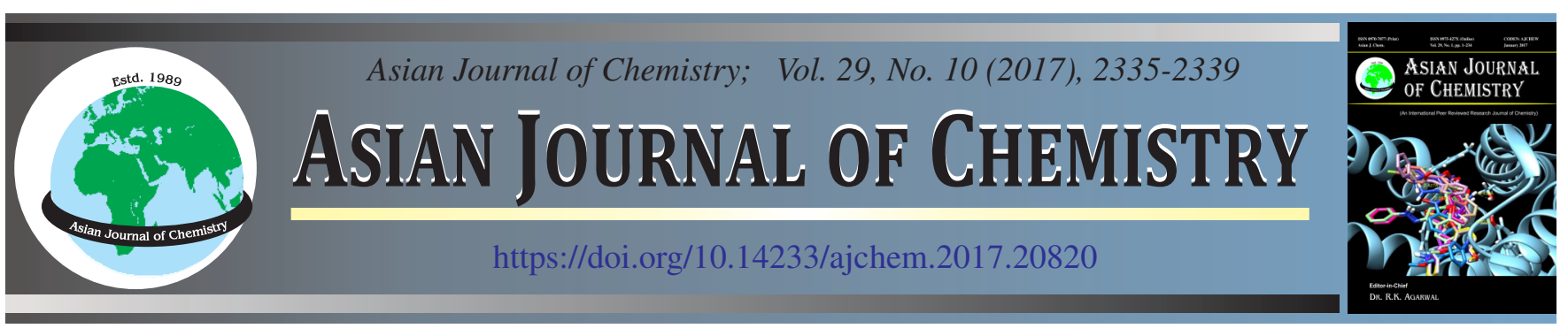

\title{
Study of Polymorphic Behaviour of 2,2'-Dichloro benzil Using Dynamic Thermal and X-Ray Diffraction Technique
}

\author{
G. Nithya ${ }^{1, *}$, R. Sudha ${ }^{1}$ and Charles C. KanaKam ${ }^{2}$
}

${ }^{1}$ Department of Chemistry, School of Basic Sciences, Vels University, Pallavaram, Chennai-600 117, India

${ }^{2}$ Department of Chemistry, Formerly Presidency College (Autonomous), Chennai-600 005, India

*Corresponding author: E-mail: nithyaranju@gmail.com

Received: 26 May 2017;

Accepted: 15 July 2017;

Published online: 31 August 2017;

AJC-18545

2,2'-Dichloro benzil (1) was synthesized and its two polymorphic forms were obtained by recrystallization from the solvents acetone/ chloroform and ethanol. The polymorphism present in the compound was confirmed by combined results of differential scanning calorimetry and single crystal X-ray crystallography. Each molecule crystallizes with one molecule in the asymmetric unit and the molecular conformations are quite different for both. The polymorph 1a crystallizes as monoclinic $\mathrm{c} 2 / \mathrm{c}$ space group in the solvent ethanol and the polymorph $\mathbf{1 b}$ crystallizes as monoclinic P21/c space group in the solvent THF. X-ray crystal structures of conformational polymorphs were analyzed to understand the interplay of molecular conformation and intermolecular lattice energy in the crystallization and stability of polymorphs.

Keywords: X-ray diffraction, Single crystal growth, Organic compounds, Conformational polymorphism.

\section{INTRODUCTION}

Many crystal forms could be obtained for organic compounds. The present scope in academic and industrial research work is focused on polymorphism [1,2]. Due to the existence of different structures in crystal, the compound shows variable physical and chemical properties for different solid forms. Polymorphism behaviour is found to exist in many compounds, while the intricacy still remains for developing some polymorphs [3-5]. The structural property correlation could be obtained by the presence of polymorphic structures which is a useful device. The remarkable effect on the corresponding solid materials is noted from the different intermolecular interactions taking place in the molecule [6].

Various polymorphs has been obtained by different crystallization methods. In some of the crystallization methods two different polymorphs were also obtained by single crystallization method. The formation of new polymorphs could be identified by using different solvents, various rates of crystallization and depending on different temperatures $[7,8]$. The formation, change in conformation and stability of the molecule were discussed. The organic molecule crystallization depends on the perceptive cohesive force of hydrogen bonding $[9,10]$. The packing of crystal shows noteworthy in weak hydrogen bonding $[11,12]$. Due to the importance of drug designing, patenting and pharmaceutical drug discovery it enlightens the pathway for polymorphic importance in industries [13,14].

The photo-physical property and intermolecular interactions were found to exist in polymorphic crystal $\mathbf{1 a}$ and $\mathbf{1 b}$. Thus the synthesis, crystal structures and photo-physical properties of the two polymorphs were studied by TG-DTA analysis. The single crystal X-ray diffraction results applied to the forms $\mathbf{1 a}$ and $\mathbf{1 b}$ were also reported.

\section{EXPERIMENTAL}

Synthesis and crystal growth of polymorph: 2,2'-Dichloro benzil (1) was synthesized in two steps (Scheme-I). The first step involves the benzoin condensation. $4 \mathrm{~g}$ of $\mathrm{KCN}$ was dissolved in $75 \mathrm{~mL}$ of water in a $1 \mathrm{~L}$ flask. To this was added $14 \mathrm{~g}(0.05 \mathrm{~mol})$ of 2,2'-dichloro benzaldeyde and $75 \mathrm{~mL}$ of $95 \%$ ethanol. The mixture formed a solution at the boiling temperature and was refluxed for $1.5 \mathrm{~h}$. Steam was then passed through the solution until all the alcohol and nearly all the unchanged aldehyde were removed. The condensed water was decanted from the product and later set away to crystallise. The product was then pressed as free as possible from oily material on a suction funnel and washed with cold alcohol. In this way about $10 \mathrm{~g}$ of crude product was obtained. The crude mixture was dissolved in hot alcohol and allowed to crystallize slowly. 2,2'-Dichloro benzoin crystallizes out as colourless, 
hexagonal crystals. From the benzoin, about $1 \mathrm{~g}$ was taken and treated with conc. nitric acid by heating in a water bath inside a fume cupboard for about $3 \mathrm{~h}$ until it is free from the smell of nitrates. It is then cooled and the obtained benzil is recrystallized using hot ethanol. Pure crystals of benzil 1a separate out (Scheme-I). The yield is about 70-80\%. The melting point of the benzil was found to be $80.2{ }^{\circ} \mathrm{C}$. The other polymorph $\mathbf{1 b}$ of the crystal is obtained by recrystallization using THF. The melting point of the benzil was found to be $113.8^{\circ} \mathrm{C}$. The molecular formula and structure of benzil was determined by IR, NMR and mass spectral analysis. The thermal behaviour of crystal was analyzed using thermogravimetric analysis. The structure of the crystal was confirmed by single crystal XRD analysis for compound $\mathbf{1 a}$ and $\mathbf{1 b}$.

Crystal structure determination: Single crystal X-ray diffraction data were collected at room temperature $\left(25(2){ }^{\circ} \mathrm{C}\right)$, using monochromatized $\mathrm{MoK}_{\alpha}$ radiation (0.71073 $\AA$ ), on a Bruker axs kappa apex2 CCD diffractometer for forms 1a and 1b. The structures were solved using program SIR92 [15] and refined using the full-matrix LS procedure with SHELXL-97 [16].

TG-DTA studies were carried out with a NETZSCH STA 409 C/CD instrument. Samples weighing 3-5 mg were heated in opened platinum pans at a rate of $10 \mathrm{~K} / \mathrm{min}$ under nitrogen gas flow of $40 \mathrm{~mL} / \mathrm{min}$.

IR spectra were recorded on a Perkin Elmer Spectrum RX I spectrometer with $\mathrm{KBr}$ discs in the $4000-450 \mathrm{~cm}^{-1}$ region. For diffuse reflectance analysis, samples weighing approximately $2 \mathrm{mg}$ were mixed with $200 \mathrm{mg} \mathrm{KBr}$ by means of an agate mortar and pestle and placed in sample cups for fast sampling.

FT-RAMAN spectrometer is a Bruker 110/S spectrometer with a multi RAM, stand alone model. The spectral range is $4000-50 \mathrm{~cm}^{-1}$. The laser source is Nd:YAG $1064 \mathrm{~nm}$. The spectrometer has a large sample compartment to accommodate different sample formats, from powder to liquid in vials.

\section{RESULTS AND DISCUSSION}

Synthesis and characterization: The polymorph 1a and 1b were obtained by recrystallization using ethanol and THF respectively. The melting point of the benzil $\mathbf{1 a}$ and $\mathbf{1 b}$ were found to be 80.2 and $113.8^{\circ} \mathrm{C}$ respectively. Both polymorphs are insoluble in water, but soluble in ethanol, chloroform and acetone. Crystals of both compounds were found to be yellow cubes. Compound 1a crystallizes in monoclinic c2/c space group and $\mathbf{1 b}$ in monoclinic P21/c space group.

Crystal structures: The structures of polymorph 1a and 1b were determined and the crystallographic data viz., selected bond distances, bond, torsion angles and refinement are presented in Table-1.
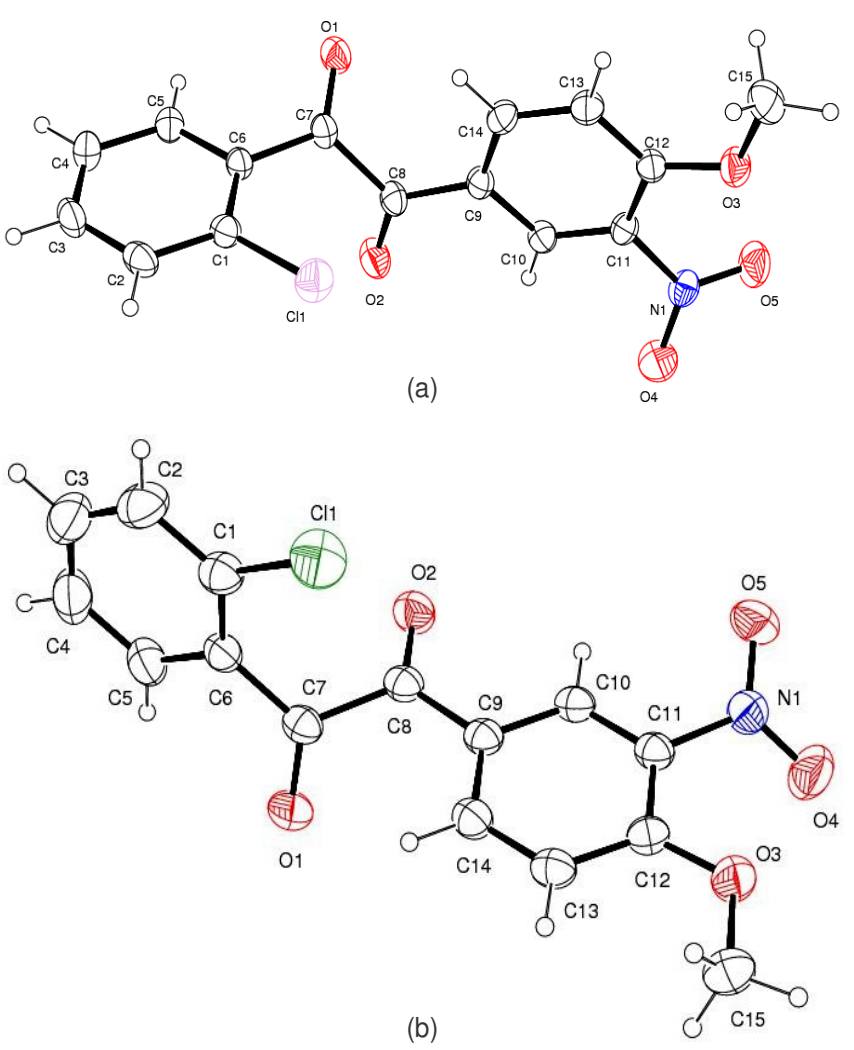

Fig. 1. Ortep diagram of polymorph $\mathbf{1 a}$ and polymorph $\mathbf{1 b}$

The polymorph 1a crystallizes in monoclinic c2/c space group and the other polymorph $\mathbf{1 b}$ was found to crystallize in the monoclinic space group P21/c. Thus, the molecules exhibit conformational polymorphism as the conformations of the molecule are described by the different sequence of torsion angles listed in Table-1. The title compound contains two ring systems, viz. chloro phenyl moiety. The torsional angle for the $\mathrm{C}=\mathrm{O}$ groups were found to be $\mathrm{C}(1)-\mathrm{C}(6)-\mathrm{C}(7)-\mathrm{O}(1)$ 144.84(15), C(5)-C(6)-C(7)-O(1) -35.29(19) and C(1)-C(6)$\mathrm{C}(7)-\mathrm{O}(1)$ 167.7(2), C(5)-C(6)-C(7)-O(1) -12.1(3) for 1a and $\mathbf{1 b}$ respectively. The torsional angles between $\mathrm{Cl}(1)-\mathrm{C}(1)-\mathrm{C}(2)-$ $\mathrm{C}(3)-177.81(12)$ and $\mathrm{Cl}(1)-\mathrm{C}(1)-\mathrm{C}(2)-\mathrm{C}(3)-178.27$ (17) for $\mathbf{1 a}$ and $\mathbf{1 b}$ shows a wide difference denoting the presence of polymorphism. ORTEP diagram of the complex is presented in Fig. 1 and crystal packing diagram is illustrated in Fig. 2.

Polymorphic structures stabilized by strong $\mathrm{C}=\mathrm{O}$ interactions and close packing were considered. The compound 2,2'-dichloro benzil has distance angle scatter plots of $\mathrm{C}=\mathrm{O}$ bonds extracted from the Cambridge Structural Database indicate that the polymorphs with a large number of symmetry independent molecules (high Z') generally have better interactions when compared with the polymorphs with lower<smiles>N#CC(=O)c1ccccc1C(=O)C(O)c1ccc(-c2ccc(C(=O)C(=O)c3ccccc3Cl)c(Cl)c2)c(Cl)c1</smiles> 


\begin{tabular}{|c|c|c|}
\hline \multicolumn{3}{|c|}{$\begin{array}{l}\text { TABLE-1 } \\
\text { CRYSTAL DATA AND SUMMARY OF DATA } \\
\text { COLLECTION AND REFINEMENT DETAILS }\end{array}$} \\
\hline Crystal data & Compound 1a & Compound 1b \\
\hline Emperical formula & $\mathrm{C}_{15} \mathrm{H}_{10} \mathrm{NO}_{5} \mathrm{Cl}$ & $\mathrm{C}_{15} \mathrm{H}_{10} \mathrm{NO}_{5} \mathrm{Cl}$ \\
\hline Formula weight $\left(\mathrm{g} \mathrm{mol}^{-1}\right)$ & 319.69 & 319.69 \\
\hline Temperature (K) & 293(2) & 293(2) \\
\hline Wavelength $(\AA)$ & 0.71073 & 0.71073 \\
\hline Crystal system & Triclinic & Monoclinic \\
\hline Space group & $\mathrm{P}-1$ & $\mathrm{P} 21 / \mathrm{c}$ \\
\hline $\mathrm{a}(\AA)$ & $7.8559(2)$ & $8.541(5)$ \\
\hline b $(\AA)$ & $8.1003(2)$ & 14.903(5) \\
\hline c $(\AA)$ & $12.4961(3)$ & $11.135(5)$ \\
\hline$\alpha\left({ }^{\circ}\right)$ & $74.8930(10)$ & $90.000(5)$ \\
\hline$\beta\left(\left(^{\circ}\right)\right.$ & $74.8090(10)$ & $92.779(5)$ \\
\hline$\gamma\left({ }^{\circ}\right)$ & $68.5930(10)$ & $90.000(5)$ \\
\hline Volume $\left(\AA^{3}\right)$ & $702.32(3)$ & $1415.7(11)$ \\
\hline $\mathrm{Z}$ & 2 & 4 \\
\hline $\mathrm{D}_{\text {calc }}\left(\mathrm{Mg} \mathrm{m}^{-3}\right)$ & 1.512 & 1.500 \\
\hline Absorption coefficient $\left(\mathrm{mm}^{-1}\right)$ & 0.296 & 0.294 \\
\hline $\mathrm{F}(000)$ & 328 & 656 \\
\hline Crystal size (mm) & $\begin{array}{l}0.30 \times 0.20 \times \\
0.20\end{array}$ & $\begin{array}{l}0.30 \times 0.20 \times \\
0.20\end{array}$ \\
\hline$\theta$ Range for data collection $\left({ }^{\circ}\right)$ & $2.75-29.64$ & $2.28-25.00$ \\
\hline Limiting indice & $\begin{array}{l}-10<=\mathrm{h}<=10 \\
-11<=\mathrm{k}<=10 \\
-12<=\mathrm{l}<=17\end{array}$ & $\begin{array}{l}-10<=\mathrm{h}<=10 \\
-17<=\mathrm{k}<=1 \\
-13<=\mathrm{l}<=13\end{array}$ \\
\hline $\begin{array}{l}\text { Reflections collected/ } \\
\text { independent [R(int)] }\end{array}$ & $\begin{array}{l}17487 / 3937 \\
{[0.0207]}\end{array}$ & $\begin{array}{l}12500 / 2488 \\
{[0.0226]}\end{array}$ \\
\hline Completeness to $\theta=29.64^{\circ}$ & $99.6 \%$ & $100.0 \%$ \\
\hline $\begin{array}{l}\text { Maximum and minimum } \\
\text { transmission }\end{array}$ & 0.951 and 0.892 & $\begin{array}{l}0.9643 \text { and } \\
0.9056\end{array}$ \\
\hline Data/restraints/parameters & $3937 / 0 / 200$ & $2488 / 0 / 200$ \\
\hline Goodness-of-fit on $\mathrm{F}^{2}$ & 1.059 & 1.040 \\
\hline Final $R$ indices $[I>2 \sigma(I)]$ & $\begin{array}{l}\mathrm{R} 1=0.0423 \\
\mathrm{wR} 2=0.1198\end{array}$ & $\begin{array}{l}\mathrm{R} 1=0.0342 \\
\mathrm{wR} 2=0.0889\end{array}$ \\
\hline $\mathrm{R}$ indices (all data) & $\begin{array}{l}\mathrm{R} 1=0.0537 \\
\mathrm{wR} 2=0.1283\end{array}$ & $\begin{array}{l}\mathrm{R} 1=0.0450 \\
\mathrm{wR} 2=0.0987\end{array}$ \\
\hline $\begin{array}{l}\text { Largest diff. peak and hole } \\
\left(\AA^{-3}\right)\end{array}$ & 0.484 and -0.408 & 0.282 and -0.275 \\
\hline
\end{tabular}

Z'values with the implication that these symmetry independent molecules have different independent conformations.

IR analysis: The IR analysis for the compound 1a and 1b shows difference in the finger print region from 1100-400 $\mathrm{cm}^{-1}$, which shows the existence of polymorphism in the title compound (Fig. 3). The analysis also gives the existence of $-\mathrm{C}=\mathrm{O}$ group at $1604,1584 \& 1685$ and $1591 \mathrm{~cm}^{-1}$ for polymorphic structure $\mathbf{1 a}$ and $\mathbf{1 b}$, respectively.

Thermal analysis: The TG-DTA curve $4 \mathrm{a}$ and $4 \mathrm{~b}$ shows the melting point at $80.2^{\circ} \mathrm{C}$ for the polymorph $1 \mathrm{a}$ and that of $113.8^{\circ} \mathrm{C}$ (Fig. 4) for the form $\mathbf{1 b}$, respectively. The difference in the temperature could be associated with the different crystal morphology of forms $\mathbf{1 a}$ and $\mathbf{1 b}$.

Raman analysis: The Raman spectrum of the two polymorphs $1 \mathbf{a}$ and $\mathbf{1 b}$ are different in the $\mathrm{C}-\mathrm{H}$ stretching region at about 3076, 1609 and $802 \mathrm{~cm}^{-1}$ and many small pattern differences in the Raman spectra below $1700 \mathrm{~cm}^{-1}$ which indicates the presence of polymorphism (Fig. 5).

\section{Conclusion}

The polymorphic crystal structure shows the presence of high energy conformers. The crystal shows effective closed packing structure and strong hydrogen bonding between them leading to high energy conformers. The existence of flexible torsions in polymorphic molecule is obtained by the destabilization of conformers in the crystal which shows enormous interest in the field of pharmaceutical drugs [14,17].

Appendix A. Supplementary material: CCDC 817058 and 879618 contain the supplementary crystallographic data for $\mathbf{1 a}$ and $\mathbf{1 b}$, respectively. These data can be obtained free of charge via http://www.ccdc.cam.ac.uk/conts/retrieving.html, or from the Cambridge Crystallographic Data Centre, 12 Union Road, Cambridge CB2 1EZ, UK; fax: (+44) 1223-336-033; or e-mail: deposit@ccdc.cam.ac.uk.
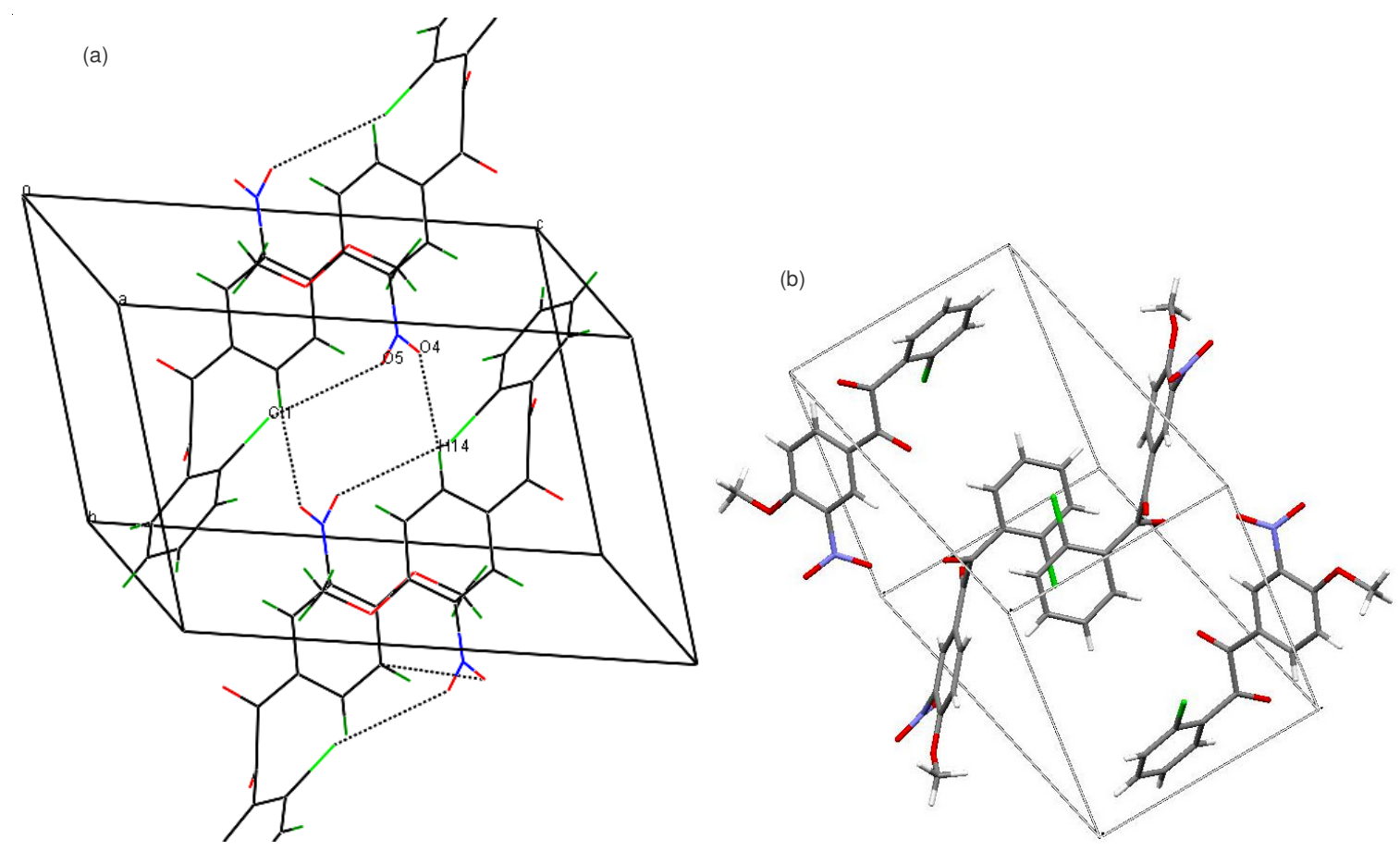

Fig. 2. Crystal packing diagram of polymorph $\mathbf{1 a}$ and polymorph $\mathbf{1 b}$ 

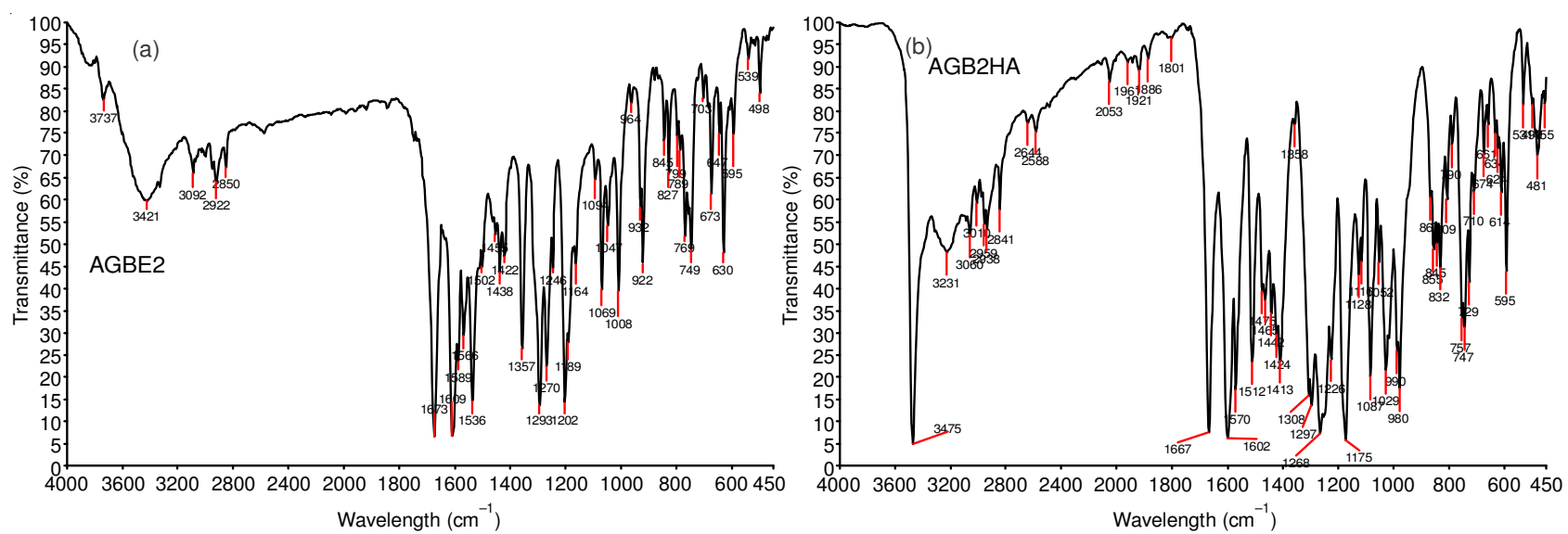

Fig. 3. IR spectra of polymorph $\mathbf{1 a}$ and $\mathbf{1 b}$
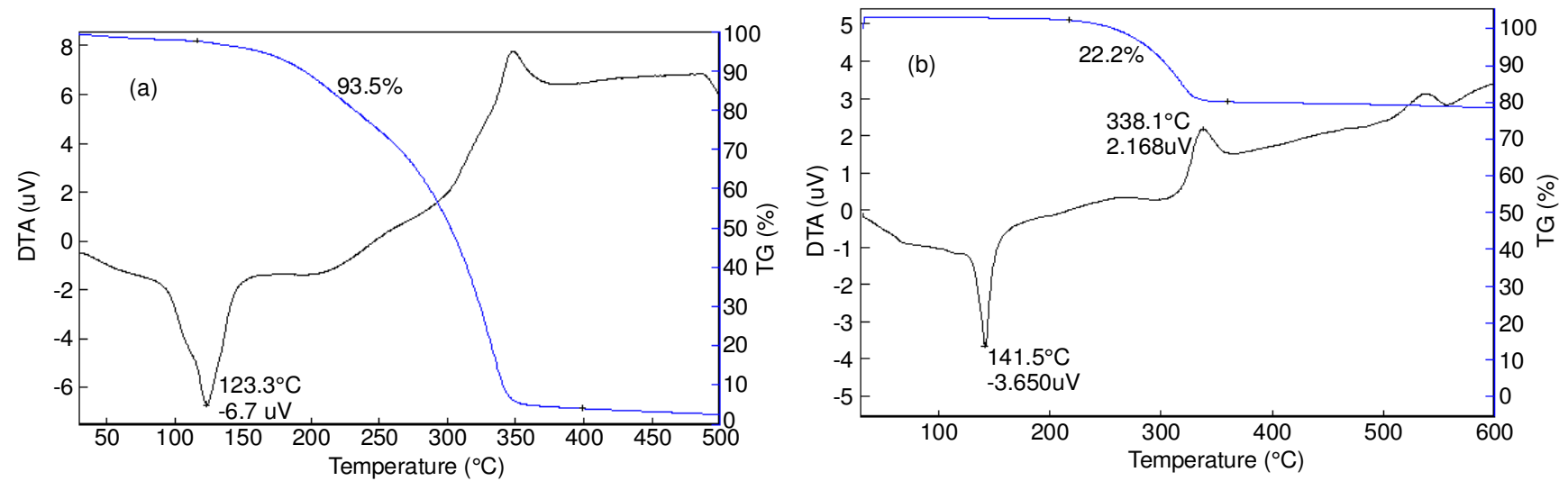

Fig. 4. TG-DTA curves of polymorph $\mathbf{1 a}$ and $\mathbf{1 b}$
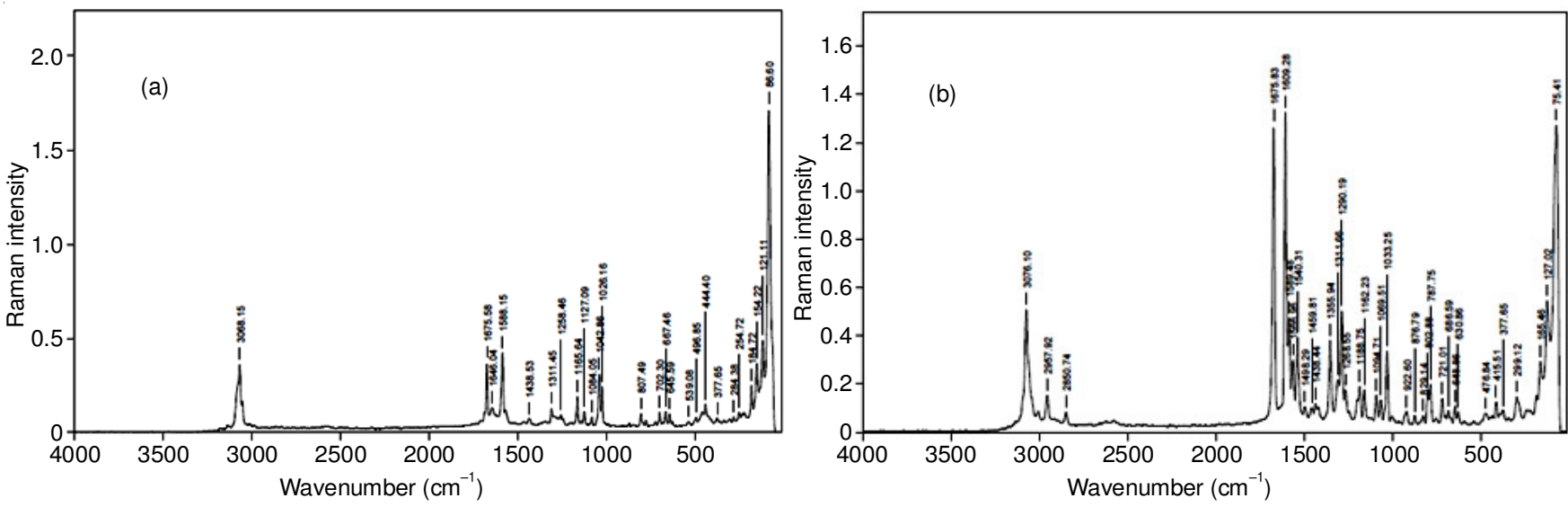

Fig. 5. Raman spectra of polymorph $\mathbf{1 a}$ and $\mathbf{1 b}$

\section{ACKNOWLEDGEMENTS}

The authors acknowledge to Vels University for providing the laboratory facilities. The authors also acknowledge to IIT SAIF, Chennai, India for data analysis.

\section{REFERENCES}

1. J. Bernstein, Polymorphism in Molecular Crystals, Clarendon Press, Oxford (2002)

2. R. Hilfiker, Polymorphism in the Pharmaceutical Industry, Wiley-VCH, Weinheim (2006).

3. J.D. Dunitz and J. Bernstein, Acc. Chem. Res., 28, 193 (1995); https://doi.org/10.1021/ar00052a005.

4. A. Bond, Curr. Opin. Solid State Mater. Sci., 13, 91 (2009); https://doi.org/10.1016/j.cossms.2009.06.004.
5. F. Grepioni, New J. Chem., 32, 1657 (2008); https://doi.org/10.1039/b814474p.

6. Y. Fan, W. Song, D. Yu, K. Ye, J. Zhang and Y. Wang, CrystEngComm, 11, 1716 (2009); https://doi.org/10.1039/b902129a.

7. A. Beheshti, W. Clegg, N. Ebrahimi Filoori and L. Russo, Acta Crystallogr. C, 67, 149 (2011); https://doi.org/10.1107/S0108270111013035.

8. A. Collas, M. Zeller and F. Blockhuys, Acta Crystallogr. C, 67, 171 (2011); https://doi.org/10.1107/S0108270111010109.

9. T. Steiner, Angew. Chem. Int. Ed., 41, 48 (2002); https://doi.org/10.1002/1521-3773(20020104)41:1<48::AID-ANIE48 $\geq 3.0 . \mathrm{CO} ; 2-\mathrm{U}$

10. (a) G.A. Jeffrey and W. Saenger, Hydrogen Bonding in Biological Structures; Springer-Verlag; Berlin (1991);

(b) G.A. Jeffrey, An Introduction to Hydrogen Bonding; Oxford University Press, New York (1997). 
11. G.R. Desiraju, Acc. Chem. Res., 35, 565 (2002); https://doi.org/10.1021/ar010054t.

12. G.R. Desiraju and T. Steiner, The Weak Hydrogen Bond in Structural Chemistry and Biology, Oxford University, UK (1999).

13. C.P. Brock and R.P. Minton, J. Am. Chem. Soc., 111, 4586 (1989); https://doi.org/10.1021/ja00195a010.

14. R. Hiltiker, Polymorphism in the Pharmaceutical Industry; Wiley-VCH: Weinheim, Germany (2006).
15. A. Altomare, G. Cascarano, C. Giacovazzo and A. Guagliardi, J. Appl. Cryst., 26, 343 (1993);

https://doi.org/10.1107/S0021889892010331.

16. G.M. Sheldrick, Acta Cryst., A64, 112 (2008); https://doi.org/10.1107/S0108767307043930.

17. H.G. Brittain, J. Pharm. Sci., 96, 705 (2007); https://doi.org/10.1002/jps.20772. 